\title{
Resilience of human settlements to climate change needs the convergence of urban planning and urban climate science
}

\author{
Xinyue $\mathrm{Ye}^{1}$ and Dev Niyogi $\mathrm{i}^{*}$ (1)
}

\begin{abstract}
The impact of climate extremes upon human settlements is expected to accelerate. There are distinct global trends for a continued rise in urban dwellers and associated infrastructure. This growth is occurring amidst the increasing risk of extreme heat, rainfall, and flooding. Therefore, it is critical that the urban development and architectural communities recognize climate impacts are expected to be experienced globally, but the cities and urban regions they help create are far more vulnerable to these extremes than nonurban regions. Designing resilient human settlements responding to climate change needs an integrated framework. The critical elements at play are climate extremes, economic growth, human mobility, and livability. Heightened public awareness of extreme weather crises and demands for a more moral climate landscape has promoted the discussion of urban climate change ethics. With the growing urgency for considering environmental justice, we need to consider a transparent, data-driven geospatial design approach that strives to balance environmental justice, climate, and economic development needs. Communities can greatly manage their vulnerabilities under climate extremes and enhance their resilience through appropriate design and planning towards long-term stability. A holistic picture of urban climate science is thus needed to be adopted by urban designers and planners as a principle to guide urban development strategy and environmental regulation in the context of a growingly interdependent world.
\end{abstract}

Keywords: Climate change, Resilience, Geospatial design, Urban climate science, Convergence

Urban areas have a higher vulnerability to climate extremes because of the preponderance of the human settlements, economic infrastructure, and the economic drivers at play. Climate extremes are manifested through high impact weather events, and there has been a spate of increasing costs associated with flooding, wildfires, winter storms, and heat stress (WMO, 2021). On average, disasters cost \$200 million per day globally, and the economic losses have increased by sevenfold considering the 1970s- 2010s period.

*Correspondence: happy1@utexas.edu

2 Department of Geological Sciences, Jackson School of Geosciences \& Department of Civil, Architectural, and Environmental Engineering, The University of Texas at Austin, Austin, USA

Full list of author information is available at the end of the article
These extremes are not geographically restricted, as was noted, for instance, with the series of widespread destructive floods and wildfires that spanned the landscapes and cities across southern California USA, many cities in Europe, and China through July 2021. The recent spate of extreme weather events and weather-related crises such as heat waves, wildfires, drought, and water shortages are notable because of their frequency and intensity and the large populations affected by them.

One of the notable findings of the IPCC (Intergovernmental Panel on Climate Change) sixth assessment report released in August 2021 is that "climate change is already affecting many weather and climate extremes". Urbanization plays an essential role in enhancing hazards, and cities are causing increase in heat (Myrup, 1969) and rainfall changes (Liu and Niyogi, 2019). The

\section{Springer}

(C) The Author(s) 2022. Open Access This article is licensed under a Creative Commons Attribution 4.0 International License, which permits use, sharing, adaptation, distribution and reproduction in any medium or format, as long as you give appropriate credit to the original author(s) and the source, provide a link to the Creative Commons licence, and indicate if changes were made. The images or other third party material in this article are included in the article's Creative Commons licence, unless indicated otherwise in a credit line to the material. If material is not included in the article's Creative Commons licence and your intended use is not permitted by statutory regulation or exceeds the permitted use, you will need to obtain permission directly from the copyright holder. To view a copy of this licence, visit http://creativecommons.org/licenses/by/4.0/. 
combination of the changing largescale climatic forcings and the more localized urban feedback creates a potent environment for severe weather and hydrological extremes. This, combined with the hazard exposure that the cities have with socioeconomic infrastructure, makes the urban settlement and climatic interactions inevitably interlinked. The IPCC summary finding quoted above is important because cities and humans often do not perceive long-term climates rather, it is the day-to-day weather events and extremes.

From the urban planning perspective, three important features contributing to the variances of the urban environment have been identified. These features are urban-rural gradient, landscape configuration, and anthropogenic heat release (Yue et al., 2012). The frequency of landscape disturbances is also an emergent feature, especially considering the large-scale wildfire, has also been spiraling upwards since the 1970s with climate warming and dramatic urbanization (Yue et al., 2021). Recently, a model-based assessment of urban impacts has been developed for extreme flood-producing storms, detecting contrasting roles of cities and climate warming in determining the space-time variability of the storms over western Europe. It highlights the interactive impacts of cities and climate warming and their role in dynamically modifying the intensity and position of moisture convergence in a changing climate (Yang et al., 2021). Similarly, studies such as Yang et al. (2016) have shown that the compact versus sprawling city growth can have a variable impact on the regional heatwaves in the future climate.

The impact of climate extremes upon human settlements is expected to accelerate. There have been global trends for a continued rise in urban dwellers and associated infrastructure. This growth is occurring amidst the increasing risk of extreme heat, rainfall, and flooding. The impacts would likely become even more catastrophic if landscape architecture and urban design continues in a "business as usual" manner without consideration of these growing epicenters of vulnerability. Therefore, it is critical that the urban development and architectural communities recognize climate impacts are expected to be experienced globally, and that the cities and urban regions they help create, are far more vulnerable to these extremes than nonurban regions. Cities create their own climate, such as the urban heat island, and have localized pollution, adding environmental stress to the atmosphere, exacerbating the warming effect seen on a regional scale. With the increasing intensity and frequency of urban flooding incidents caused by hurricanes or storms, legacy cities with many brownfields, vacant lands, and outdated infrastructure will also need to deal with growing risks of flood-related contamination (Nair et al., 2019; Zhu \& Newman, 2021). The urban disaster caused by an increasing number of extreme weather episodes is an international challenge and a significant source of fatalities, property loss, social disruption and inequality. Bridging the silos within climate science and urban science communities and reducing the gap between research and practice can make it possible to achieve a resilient urban environment. This required connection needs to be addressed as an integrated system to deal with the pressing issue of extreme weather on growing urban neighborhoods.

Extreme weather is coupled with the extensive exploitation of natural resources as well as (formal and informal) human settlements sprawl in this increasingly urbanized world. The solutions that the city often considers are embedded in the well-known debates around density versus sprawl, monocentric versus polymorphic cities, and on the climate end: the issues of mitigation and adaptation. Moreover, the burden of climate hazards has fallen disproportionately on poorer and less resourceful individuals and communities in the city locales. There is increasing evidence illustrating that people and cities do not uniformly benefit from the level and degree of protection from hazards. The distributional impact of natural catastrophes or extreme weather events is historically, racially, and economically stacked against certain populations and communities that are often more vulnerable to shocks (Mansury et al., 2021).

Urban growth has essentially changed the urban fiber with growing income differentials and rising social structural gaps. Searching for the appropriate equilibrium between urban development and environmental/ climate justice is an emerging and pressing issue in its unprecedented uneven socioeconomic and environmental transformation. At the same time, there is a large knowledge gap between climate scientists, urban planners, and the architectural community. Specifically, spatial inequality of limited resources (such as access to water, air, energy, and land) has been formed across various social groups, exacerbated by the community's unequal exposure to the increasing climate hazards. In other words, large cities across the world are experiencing dramatic spatial and social reconfiguration, differentiation and polarization, which give rise to different environmental benefits based on people's economic status with worsening of extreme weather.

Meanwhile, income inequality has dramatically risen within urban areas, causing an imbalanced community system to cope with climate change. With the global economic system moving towards a market-based, entrepreneurial state, economically rewarding activities are encouraged, admired, and pursued by government agencies and individuals. Hence, the well-being of the 
marginalized and disadvantaged people is not adequately addressed under extreme weather. Heightened public awareness of extreme weather crises and demands for a more moral climate landscape has promoted the discussion of ethics and urban climate change issues. Working together with the urban planning, architecture, and urban climate community can help address the challenge of uneven development and environmental stress, climate change adaptation and mitigation in this continued dynamic urban system.

Increases in extreme weather events (such as heat waves, wildfires, droughts, flooding, and hurricanes) are just the most apparent threats due to climate hazards and global warming. The impacts due to pandemics or the health toll due to air quality exposure are still emerging. Averting catastrophic climate change is possible and has risen in the domestic and international agenda. As a result, integrating climate science and urban science should be a priority for developing a resilient society, and an infrastructure that supports resilience. Climate change is not just an environmental issue but a public policy issue, which is closely associated with environmental equity and fairness across urban social hierarchies. Minority groups and low-income populations as well as marginalized regions, bear adverse health and environmental impacts from the climate hazard. Such situations contribute to a feedback loop to continued warming and accumulated climate injustice.

Empowering the public and various stakeholders to actively combat climate change is vital to ensure sustainable urban development. Communicating the extreme weather risk is challenging because it involves collecting a large volume of climate and urban literature, crosschecking the information from different sources, and following the rapidly growing new studies in both climate and urban research. Such scientific knowledge scatters in many places such as academic papers, news articles, and online resources. The volume of the past studies is enormous, and resources related to climate change emerge at a rapid pace. Furthermore, many entities and relations regarding climate change and urban dynamics are not publicly available or not easily searchable, requiring domain knowledge in ontology and knowledge graph building. The different information sources could also contradict each other, leading to confusion in knowledge understanding. Hence, collecting, digesting and keeping the knowledge updated is a daunting task, preventing the urban designers/planners, stakeholders, decision-makers from understanding the broad situation of extreme weather, answering the specific questions related to their major concerns, and being informed to make actions.

In summary, designing resilient human settlements responding to climate change needs an integrated framework. The critical elements at play are climate extremes, economic growth, human mobility, and livability. Heightened public awareness of extreme weather crises and demands for a more moral climate landscape has promoted the discussion of urban climate change ethics. With the growing urgency for considering environmental justice, we need to consider a transparent, data-driven geospatial design approach that strives to balance environmental justice, climate, and economic development needs. Communities can greatly diminish their vulnerabilities under climate extremes and enhance their resilience through appropriate design and planning towards long-term stability. For instance, an AI (Artificial Intelligence)-driven platform for flood resilience design and planning has been conceptualized to integrate multiple disciplines (architectural design, landscape architecture, urban planning, geography, and computer science) to examine the climate resilient issues ranging from micro to macro scales (Ye et al., 2021). AI facilities novel methods of urban data acquisition and data fusion, using IoT (Internet of things), mobile phones, and crowdsourcing (Kaginalkar et al., 2021).

Climate science has typically been viewed as a global and large-scale assessment primarily involving geophysical aspects, while urban science is at a much more local scale involving social and human systems. The interface now emerging with urban climate is where a confluence of geophysics and urban social science needs to occur. For example, by modeling one of the deadliest floods (mid-July 2021 with more than 200 fatalities) in European history, Yang et al. (2021) found that the rainfall anomalies caused by urban conditions are more obvious with climate warming compared to previous scenarios.

Urban areas are at an economic advantage compared to rural regions but are more vulnerable to climate impacts. This feature suggests that it is not the access to funds which is the limiting factor - it is the lack of a framework and a definition of a sustainable urban system that is likely the weak link. As Gonzalez and Niyogi (2021) state, "The urban climate era has evolved from its initial focus on urban heat island assessments and boundary layer feedbacks to being a critical component of the weather, air quality, and broader earth system modeling and assessment framework. Beyond the models and research endeavors, the societal need for more localized, decisionrelevant information has exponentially increased and is expected to grow in the coming decade". We are now at a critical point for the climate scientists, urban scientists, and city leaders to work together to reimagine the immediate future. Averting catastrophic climate change has risen on the domestic and international agenda, and it presents an opportunity for the integration of climate science and urban science to have significantly more 
influence over landscape architecture, urban planning, policy debates, and decision-making. Linking the issues of extreme weather and climate change to the problem of development is more likely to achieve the win-win goal than treating climate change separately from dramatic urbanization. As pointed out by Yang et al. (2021), "The role of cities has not been adequately considered in the attribution analysis of weather extremes. Future adaptation and mitigation strategies to climate change need to consider the emerging urban-rural contrasts in the exposure and vulnerability of hydrometeorological extremes". A holistic picture of urban climate science is thus needed to be adopted by urban designers and planners as a principle to guide urban development strategy and environmental regulation in the context of a growingly interdependent world. For instance, a 'fit for the purpose' multi-technology framework can be developed to help decision-makers and citizens to action in real-time in emerging smart cities.

\section{Acknowledgements}

XY and DN acknowledge support from NSF OAC-1835739 and SMA-2122054, NASA Interdisciplinary Sciences 80NSSC20K1262 and 80NSSC20K1268, University of Texas John E. "Brick" Elliott Centennial Endowed Professorship, Texas A\&M University Harold L. Adams Interdisciplinary Professorship Research Fund.

\section{Code availability}

Not Applicable.

\section{Authors' contributions}

$X Y$ and DN co-wrote the opinion. The author(s) read and approved the final manuscript.

\section{Funding}

NSF OAC-1835739 and SMA-2122054, NASA Interdisciplinary Sciences 80NSSC20K1262 and 80NSSC20K1268, University of Texas John E. "Brick" Elliott Centennial Endowed Professorship, Texas A\&M University Harold L. Adams Interdisciplinary Professorship Research Fund.

\section{Availability of data and materials}

Not Applicable.

\section{Declarations}

\section{Competing interests}

The author declares that he/she has no competing interests.

\section{Author details}

'Department of Landscape Architecture and Urban Planning \& Department of Geography, Texas A\&M University, College Station, USA. ${ }^{2}$ Department of Geological Sciences, Jackson School of Geosciences \& Department of Civil Architectural, and Environmental Engineering, The University of Texas at Austin, Austin, USA.

Received: 22 December 2021 Accepted: 3 January 2022

Published online: 14 February 2022

\section{References}

Gonzalez, J. E., \& Niyogi, D. (2021). Urban climate is central to the next-generation weather and climate models, field studies, and societal needs. https://doi. org/10.1016/j.uclim.2021.100873
Kaginalkar, A., Kumar, S., Gargava, P., \& Niyogi, D. (2021). Review of urban computing in air quality management as smart city service: An integrated loT, $\mathrm{Al}$, and cloud technology perspective. Urban Climate, 39, 100972.

Liu, J., \& Niyogi, D. (2019) Meta-analysis of urbanization impact on rainfall modification. Scientific reports, 9(1), 1-14.

Mansury, Y., Ye, X., \& Yoon, D. K. (2021). Structural path analysis of extreme weather events: An application to hurricane Katrina and Superstorm Sandy. Applied Geography, 136, 102561.

Myrup, L. O. (1969). A numerical model of the urban heat island. Journal of Applied Meteorology and Climatology, 8(6), 908-918.

Nair, U. S., Rappin, E., Foshee, E., Smith, W., Pielke, R. A., Mahmood, R., Case, J. L., Blankenship, C. B., Shepherd, M., Santanello, J. A., \& Niyogi, D. (2019). Influence of land cover and soil moisture based Brown Ocean effect on an extreme rainfall event from a Louisiana Gulf Coast tropical system. Scientific Reports, 9(1), 1-10.

WMO. (2021). The atlas of mortality and economic losses from weather, climate and water extremes (1970-2019), WMO- No (Vol. 1267) ISBN: 978-92-6311267-5, available from https://ibrary.wmo.int/doc_num.php?explnum_ $\mathrm{id}=10769$

Yang, L., Ni, G., Tian, F., \& Niyogi, D. (2021). Urbanization exacerbated rainfall over European suburbs under a warming climate. Geophysical Research Letters, e2021GL095987.

Yang, L., Niyogi, D., Tewari, M., Aliaga, D., Chen, F., Tian, F., \& Ni, G. (2016). Contrasting impacts of urban forms on the future thermal environment: Example of Beijing metropolitan area. Environmental Research Letters, 11(3), 034018.

Ye, X., Wang, S., Lu, Z., Song, Y., \& Yu, S. (2021). Towards an Al-driven framework for multi-scale urban flood resilience planning and design. Computational Urban Science, 1(1), 1-12.

Yue, W., Liu, Y., Fan, P., Ye, X., \&Wu, C. (2012). Assessing spatial pattern of urban thermal environment in Shanghai, China. Stochastic Environmental Research and Risk Assessment, 26(7), 899-911.

Yue, Y., Dong, K., Zhao, X., \& Ye, X. (2021). Assessing wild fire risk in the United States using social media data. Journal of Risk Research., 24(8), 972-986. https://doi.org/10.1080/13669877.2019.1569098

Zhu, R., \& Newman, G. (2021). The projected impacts of smart decline on urban runoff contamination levels. Computational Urban Science, 1(1), 1-20.

\section{Publisher's Note}

Springer Nature remains neutral with regard to jurisdictional claims in published maps and institutional affiliations. 